Incidence, Predictors, and Significance of Abnormal Cardiac Enzyme Rise in Patients Treated With Bypass Surgery in the Arterial Revascularization Therapies Study (ARTS)

Marco A. Costa, Ronald G. Carere, Samuel V. Lichtenstein, David P. Foley, Vincent de Valk, Wietze Lindenboom, Paul C.H. Roose, Theo R. van Geldorp, Carlos Macaya,

José L. Castanon, Francisco Fernandez-Avilèz, Jesús Herreros Gonzáles, Günter Heyer, Felix Unger and Patrick W. Serruys

Circulation 2001;104;2689-2693

DOI: $10.1161 / \mathrm{hc} 4701.099789$

Circulation is published by the American Heart Association. 7272 Greenville Avenue, Dallas, TX 72514

Copyright @ 2001 American Heart Association. All rights reserved. Print ISSN: 0009-7322. Online ISSN: $1524-4539$

The online version of this article, along with updated information and services, is located on the World Wide Web at:

http://circ.ahajournals.org/cgi/content/full/104/22/2689

Subscriptions: Information about subscribing to Circulation is online at http://circ.ahajournals.org/subsriptions/

Permissions: Permissions \& Rights Desk, Lippincott Williams \& Wilkins, 351 West Camden Street, Baltimore, MD 21202-2436. Phone 410-5280-4050. Fax: 410-528-8550. Email:

journalpermissions@1ww.com

Reprints: Information about reprints can be found online at http://www.lww.com/static/html/reprints.html 


\title{
Incidence, Predictors, and Significance of Abnormal Cardiac Enzyme Rise in Patients Treated With Bypass Surgery in the Arterial Revascularization Therapies Study (ARTS)
}

\author{
Marco A. Costa, MD, PhD; Ronald G. Carere, MD; Samuel V. Lichtenstein, MD; \\ David P. Foley, MD, MB, MRCPI, PhD; Vincent de Valk, PhD; Wietze Lindenboom, MSc; \\ Paul C.H. Roose, MD; Theo R. van Geldorp, MD; Carlos Macaya, MD; José L. Castanon, MD; \\ Francisco Fernandez-Avilèz, MD; Jesús Herreros Gonzáles, MD; Günter Heyer, MD; Felix Unger, MD; \\ Patrick W. Serruys, MD, PhD; on behalf of ARTS study group \\ Background-Although it has been suggested that elevation of CK-MB after percutaneous coronary intervention is \\ associated with adverse clinical outcomes, limited data are available in the setting of coronary bypass grafting. The aim \\ of the present study was to determine the incidence, predictors, and prognostic significance of CK-MB elevation \\ following multivessel coronary bypass grafting (CABG). \\ Methods and Results - The population comprises 496 patients with multivessel coronary disease assigned to CABG in the \\ Arterial Revascularization Therapies Study (ARTS). CK-MB was prospectively measured at 6, 12, and 18 hours after \\ the procedure. Thirty-day and 1-year clinical follow-up were performed. Abnormal CK-MB elevation occurred in 61.9\% \\ of the patients. Patients with increased cardiac-enzyme levels after CABG were at increased risk of both death and repeat \\ myocardial infarction within the first 30 days $(P=0.001)$. CK-MB elevation was also independently related to late \\ adverse outcome $(P=0.009$, OR=0.64). \\ Conclusions-Increased concentrations of CK-MB, which are often dismissed as inconsequential in the setting of \\ multivessel CABG, appear to occur very frequently and are associated with a significant increase in both repeat \\ myocardial infarction and death beyond the immediate perioperative period. (Circulation. 2001;104:2689-2693.)
}

Key Words: cardiopulmonary bypass a creatine kinase a coronary disease

$\mathrm{M}$ yocardial necrosis has classically been detected by measurement of the serum creatine kinase $(\mathrm{CK})$ and specifically the $\mathrm{MB}$ isoenzyme (CK-MB), which is more sensitive and specific. ${ }^{1-4}$ Elevation of CK-MB following percutaneous coronary revascularization procedures has been demonstrated to occur in $6 \%$ to $34 \%$ of patients. ${ }^{5-10}$

A recent consensus report has proposed a CK-MB threshold of 3 times the upper limit of normal for percutaneous revascularization and 5 times for bypass surgery as a marker for periprocedural myocardial infarction and subsequent increased risk of adverse events. ${ }^{1}$ This recommendation is derived mainly from reports on the prognostic significance of cardiac enzyme elevation after balloon angioplasty or directional coronary atherectomy (DCA). At present, no definitive conclusion can be drawn concerning the prognostic significance of CK-MB elevation following coronary bypass surgery because of a paucity of data relating to this issue..$^{1,11,12}$
The Arterial Revascularization Therapies Study (ARTS) was designed to compare coronary artery bypass grafting $(\mathrm{CABG})$ and stenting for the treatment of patients with multivessel coronary disease. ${ }^{13}$ The aims of the present investigation were to determine the incidence, predictors, and prognostic significance of CK-MB elevation following multivessel CABG.

\section{Methods}

\begin{abstract}
ARTS Trial Design
Between April 1997 and June 1998, 1205 patients were randomized to either stent implantation $(n=600)$ or $\mathrm{CABG}(\mathrm{n}=605)$ at 67 participating centers worldwide. ${ }^{13}$ Only patients who had no previous angioplasty or CABG procedures were included. The indications for revascularization were silent ischemia, stable or unstable angina pectoris, and the presence of at least 2 de novo lesions located in different major epicardial coronary arteries potentially amenable to stent implantation. Patients with left main stem stenosis, impaired
\end{abstract}

Received July 10, 2001; revision received September 26, 2001; accepted September 26, 2001.

From the University Hospital Dijkzigt (M.AC., D.P.F., P.W.S.), Thoraxcentrum, Rotterdam, the Netherlands; the University of Florida (M.A.C.), Shands Jacksonville; St Paul's Hospital (R.G.C., S.V.L.), Vancouver, Canada; Cardialysis BV (V.d.V., W.L.), Rotterdam, the Netherlands; the Medical Center De Klokkenberg (P.C.H.R., T.R.v.G.), Breda, the Netherlands; Hospital Clinico San Carlos (C.M., J.L.C.), Madrid, Spain; Hospital Universitario de Valladolid (F.F.-A., J.H.G.), Spain; and Landeskrankenanstalten Salzburg (G.H., F.U.), Salzburg, Austria.

Correspondence to Prof P.W. Serruys, MD, PhD, Head of the Interventional Cardiology Dept, Heartcenter/Erasmus University Rotterdam, Thoraxcenter, Bd-408, Dr Molewaterplein 40-3015 GD, Rotterdam, the Netherlands. E-mail serruys@card.azr.nl

(C) 2001 American Heart Association, Inc.

Circulation is available at http://www.circulationaha.org 
left ventricular function (left ventricular ejection fraction $<30 \%$,), prior cerebrovascular accident (CVA), myocardial infarction within the week preceding randomization, severe hepatic or renal disease, or patients who needed concomitant major surgery were not included in the study. All patients gave written informed consent.

Bypass surgery followed current standard techniques, preferably using the left internal mammary artery for revascularization of the left anterior descending coronary artery. ${ }^{13}$

\section{Data Collection}

Angiographic data, including the characteristics of each lesion and target coronary segment were adjudicated by an independent core laboratory (Cardialysis BV, Rotterdam). Myocardial infarction (MI) occurring within 7 days of the procedures was defined as the appearance of a new Q-wave and cardiac enzymes greater than 5 times the upper limit of normal or a ratio of peak CK-MB/CK exceeding 0.1 . To define a MI after 7 days, either the electrocardiographic or enzymatic criteria sufficed. The Minnesota criteria code for pathological Q-waves was used, and the EKGs were analyzed by an independent core laboratory.

Case report forms were verified and compared with each medical record by the study monitors. Clinical events were adjudicated by an independent committee.

\section{CK-MB Study Design}

All patients enrolled in the ARTS trial and randomized to CABG were eligible for the present study, a post hoc analysis. Patients were excluded

\section{TABLE 1. Clinical and Procedure-Related Variables}

\begin{tabular}{|c|c|}
\hline Variables & $\begin{array}{c}\text { CABG } \\
(\mathrm{n}=496)\end{array}$ \\
\hline \multicolumn{2}{|l|}{ Clinical characteristics } \\
\hline Age, y & 61.5 \\
\hline Male, \% & 75 \\
\hline Unstable angina, \% & 36.1 \\
\hline Previous myocardial infarction, \% & 40.9 \\
\hline Diabetes mellitus, \% & 16.5 \\
\hline Hypertension, \% & 45.2 \\
\hline Hypercholesterolemia, \% & 58.3 \\
\hline Family history, \% & 42.3 \\
\hline Peripheral vascular disease, $\%$ & 5.0 \\
\hline Current smoking, \% & 24.4 \\
\hline Left ventricular ejection fraction, $\%$ & 60.8 \\
\hline \multicolumn{2}{|l|}{ Procedural-related variables } \\
\hline Number of segments diseased ${ }^{*}$ & $2.8 \pm 1$ \\
\hline Number of segments treated* & $2.7 \pm 0.8$ \\
\hline Number of distal anastomoses* & $2.8 \pm 0.8$ \\
\hline \multicolumn{2}{|l|}{ Target vessel } \\
\hline Left anterior descending, $\%$ & 91 \\
\hline Right coronary artery, \% & 72 \\
\hline Left circumflex, \% & 72 \\
\hline At least 1 arterial conduit used, $\%$ & 90 \\
\hline Left internal mammary artery, $\%$ & 90 \\
\hline Arterial conduit on LAD, \% & 95 \\
\hline Duration of aorta cross-clamp, $\min ^{*}$ & $44.5 \pm 24$ \\
\hline \multicolumn{2}{|l|}{ Type of myocardial protection } \\
\hline Crystalloid, \% & 57 \\
\hline Blood, \% & 34 \\
\hline Intermittent cross-clamping, $\%$ & 19 \\
\hline
\end{tabular}

*Numbers are expressed as mean \pm SD. if they had elevated cardiac enzymes prior to the procedure $(n=47)$, were not treated according to randomization $(n=26)$, or if measurements of cardiac enzymes were not available $(n=36)$ in the $C A B G$ group.

Blood samples were collected for CK-MB measurements at screening and at 6,12 , and 18 hours after the procedure. If enzymes were found to be elevated, CK-MB levels were followed for a longer duration to determine the actual peak value. These measurements were performed according to the local laboratory standards. In order to standardize the analyses at different sites, enzyme levels were expressed based on the local normal laboratory values. Patients were stratified into 4 categories of CK-MB levels: normal, 1 to $3, \geq 3$ to 5 , and more than 5 times the upper limit of normal in each treatment arm. Because of its low specificity in detecting myocardial injury, particularly in patients post CABG, measurements of total CK were not evaluated.

Every itemized clinical event including death, MI, any repeat revascularization as well as the combined major cardiac (death, MI, and repeated revascularization) and cerebrovascular events (MACCE) occurring $>24$ hours after the procedures were counted for 30-day and 1-year follow-up analyses. Any event occurring within 24 hours after the procedure was not counted as an adverse event in order to avoid the potential confounding influence of the immediate sequelae of procedural complications.

\section{Statistical Analysis}

Statistical analysis was performed using the SAS 6.12 (SAS Institute Inc). Continuous variables are expressed as mean \pm SD. Binary outcome variables are reported as frequencies and percentages. In the 30 -day analysis, $\chi^{2}$ analysis was performed according to MantelHaenszel for comparisons among categorical variables of the subgroups. For 1-year follow-up, events were depicted with KaplanMeier curves using the SAS Lifetest procedure, and probability values were defined by means of $\log$ rank analysis. Multivariate logistic regression models were constructed using baseline characteristics as well as procedure-related factors to identify independent predictors of CK-MB rise after the procedure. Another multivariate logistic regression model was constructed to determine whether the level of cardiac enzyme (CK-MB) after the procedure was an independent risk-factor for late events. A value of $P<0.05$ was considered significant.

\section{Results}

In the present study, 496 patients treated with CABG were included. Baseline characteristics are shown in Table 1.

\section{Incidence and Predictors of Postprocedure CK-MB Release}

Overall, abnormal CK-MB elevation occurred in $61.9 \%$ of patients treated with $\mathrm{CABG}$. Figure 1 illustrates the stratification of CK-MB elevation.

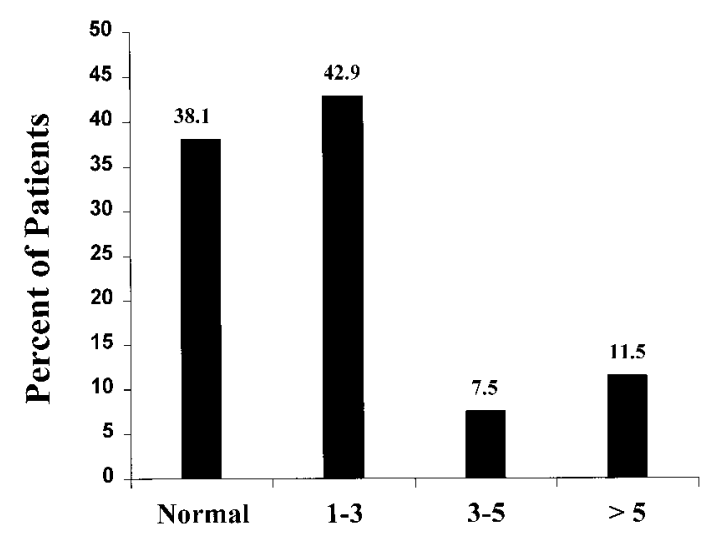

Figure 1. Frequency of CK-MB elevation after bypass surgery, according to the prestratified categories $(n=4)$ of CK-MB levels. 
TABLE 2. Independent Predictors of CK-MB Elevation After CABG

\begin{tabular}{lcccc}
\hline & Frequency & $\chi^{2}$ & $P$-value & Odds Ratio \\
\hline Use of oral short-acting nitrates & $141 / 496$ & 14 & 0.0002 & 2.13 \\
Angiographic thrombus at screening & $19 / 487$ & 10.6 & 0.001 & 0.14 \\
Emergency procedure & $13 / 487$ & 9.2 & 0.002 & 5.88 \\
Target lesion in the first marginal & $54 / 496$ & 9.2 & 0.002 & 2.38 \\
branch & & & & \\
Need for inotropic agents postprocedure & $23 / 496$ & 8 & 0.005 & 3.45 \\
Use of ACE inhibitors & $116 / 496$ & 7.1 & 0.008 & 0.56 \\
Diabetes mellitus & $82 / 496$ & 6.6 & 0.01 & 0.53 \\
Unstable angina & $171 / 496$ & 6.6 & 0.01 & 0.57 \\
Angulation of the target segments $>90^{\circ}$ & $43 / 496$ & 5.8 & 0.02 & 2.08 \\
Duration of aortic cross-clamping, min & & 5.3 & 0.02 & 1.01 \\
Anastomosis in the mid-third of LAD & $380 / 496$ & 4.8 & 0.03 & 0.62 \\
Totally occluded vessels, $>3$ months & $16 / 487$ & 4.9 & 0.03 & 2.94 \\
\hline
\end{tabular}

ACE indicates angiotensin converting enzyme, LAD, left anterior descending.

Factors found to be significant in the univariate analysis $(n=22)$ were entered into the multivariate logistic model. Several independent risk-factors were found to predict CK-MB elevation after the procedure (Table 2): use of oral short-acting nitrates during hospitalization, revascularization priority (emergency), need for inotropic agents after the procedure, lesion location in the first circumflex marginal or intermediate branch, target segments with angulation $>90$ degrees, duration of aortic cross-clamping, and number of totally occluded vessels ( $>3$ months). Some variables were found to be protective against CK-MB rise after the procedure: angiographic evidence of thrombus in the target lesion, the use of angiotensin converting enzyme (ACE) inhibitors during hospitalization, diabetes mellitus, unstable angina, and anastomosis in the mid-third of left anterior descending coronary artery.

\section{Prognostic Significance of Increased CK-MB Concentration}

Table 3 summarizes the incidence of early adverse events after CABG, according to the stratified levels of CK-MB elevation. Patients with increased cardiac-enzyme levels after CABG were at high risk of death as well as repeat MI. Patients with the highest level ( $>5$ times normal) of CK-MB showed an early mortality rate of $7 \%$. Patients with CK-MB levels 3 to 5 times normal also had a trend toward an increased mortality rate as compared with patients with mild ( $>1$ to 3 times normal) CK-MB elevations $(P=0.065)$.
All deaths were cardiovascular in origin. One patient with CK-MB levels $>1$ to $3 \times$ normal died 2 days later after arrhythmia and cardiac arrest. One patient with CK-MB elevation 3 to $5 \times$ normal developed a bowel infarction and died after 1 month due to arrhythmias and renal failure. A second patient with $\mathrm{CK}-\mathrm{MB}$ levels 3 to $5 \times$ normal had a cardiac arrest 48 to 60 hours postoperatively. Among patients with CK-MB levels $>5 \times$ normal, 4 patients died at 2, 3, 18, and 21 days postoperatively due to postoperative acute respiratory failure, thrombotic small bowel infarction and metabolic dysfunction, myocardial infarction, and pulmonary embolism with cardiogenic shock, respectively.

One-year follow-up data were obtained in all patients. Patients with postprocedure CK-MB elevation after CABG were more likely to have adverse events (Figure 2). A strong relationship between cardiac enzyme levels and each itemized clinical event, death, or repeat MI was observed in the CABG group (Figure 3). Mortality rates were $1.1 \%, 0.5 \%$, $5.4 \%$, and $10.5 \%$, the incidences of MIs were $1.1 \%, 1.9 \%$, $2.7 \%$, and $12.3 \%$, CVA occurred in $1.6 \%, 1.9 \%, 2.7 \%$, and $1.8 \%$, whereas repeat revascularization occurred in $3.7 \%$, $2.8 \%, 0 \%$, and $3.5 \%$ of patients with CK-MB levels that were normal, $>1$ to $3, \geq 3$ to 5 , and $>5$ times normal, respectively.

\section{Predictors of Late Outcome}

In order to determine whether elevated CK-MB levels should be interpreted as an independent marker of worse clinical outcomes (1-year MACCE) in patients treated with CABG, a

TABLE 3. Incidence of Events up to 30 Days After CABG

\begin{tabular}{lcccccc}
\hline CK-MB Level & $\begin{array}{c}\text { Normal } \\
(\mathrm{n}=189)\end{array}$ & $\begin{array}{c}>1-3 \\
(\mathrm{n}=213)\end{array}$ & $\begin{array}{c}3-5 \\
(\mathrm{n}=37)\end{array}$ & $\begin{array}{c}>5 \\
(\mathrm{n}=57)\end{array}$ & $\begin{array}{c}\text { Any CK-MB Elevation } \\
(\mathrm{n}=307)\end{array}$ & $P^{*}$ \\
\hline Death, \% & 0 & 0.5 & 5.4 & 7.0 & 2.3 & 0.001 \\
Myocardial infarction, \% & 1.1 & 1.4 & 2.7 & 12.3 & 3.9 & 0.001 \\
CVA, \% & 1.1 & 1.4 & 0 & 1.8 & 1.3 & $\mathrm{NS}$ \\
Any revascularization, \% & 0.5 & 0 & 0 & 3.5 & 0.7 & $\mathrm{NS}$ \\
\hline
\end{tabular}

CVA indicates cerebrovascular accident.

*Comparison between the 4 groups. 


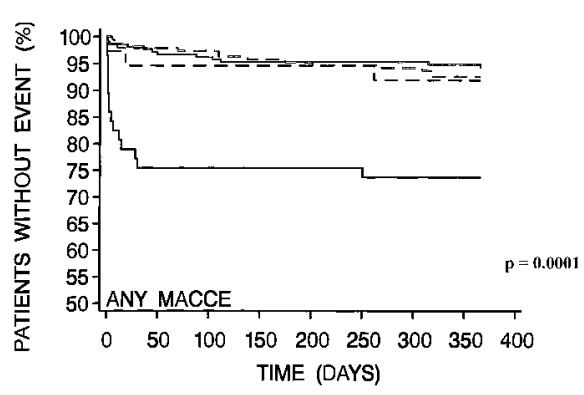

Figure 2. Kaplan-Meier curves illustrating the incidence of MACCE at 1-year follow-up in patients with normal CK-MB levels (dashed gray lines), $>1$ to 3 times normal (solid gray lines), $\geq 3$ to 5 times normal (dashed black lines), and $>5$ times normal (solid black lines). The $P$-value refers to the comparison among the 4 groups.

multivariate logistic regression was performed. The peak postprocedural cardiac enzyme level was strongly correlated with adverse events after CABG $\left(P=0.009\right.$, OR=1.56, $\left.\chi^{2}=6.8\right)$. Other factors were also found to be predictors of 1-year MACCE, as follows: emergency procedure $(P=0.002$, $\left.\mathrm{OR}=10.1, \chi^{2}=9.9\right)$, age $\left(\mathrm{n}=13, P=0.01, \mathrm{OR}=1.05, \chi^{2}=6.3\right)$, and abnormal monocyte levels $(\mathrm{n}=20, P=0.004, \mathrm{OR}=4.8$, $\left.\chi^{2}=8.3\right)$.

\section{Discussion}

In the present study, patients treated with $\mathrm{CABG}$ experienced a high incidence of postprocedure CK-MB elevation. CK-MB elevation $>1$ to 3 times normal was a frequent finding (42.9\%), and only $38.1 \%$ of the patients had normal levels of CK-MB postoperatively (Figure 1). A small amount of CK-MB (2\% to $4 \%$ ) may be measurable after skeletal muscle injury, ${ }^{14}$ and the manipulation of the heart during operation may also induce a CK-MB leak. ${ }^{15}$ A small rise of CK-MB without irreversible myocardial necrosis has also been reported. ${ }^{16}$

\section{Predictors of CK-MB Elevation}

A number of factors, including anatomical and procedurerelated variables, independently influenced the level of CK-MB after CABG. The use of oral short-acting nitrates was the strongest predictor of abnormal CK-MB elevation after surgery. This may reflect a deleterious effect of these agents on myocardial protection during surgery as described by others. ${ }^{17}$ Conversely, the use of angiotensin converting enzyme (ACE) inhibitors had a protective effect on the myocardium. ${ }^{18}$ Additional prospective investigations are required to address this question.
Unstable angina, angiographic evidence of thrombus, and diabetes mellitus at screening were identified as protective factors against CK-MB elevation following surgery. Some previous data may support this paradoxical finding. First, preconditioning ischemia ${ }^{19,20}$ may prevent CK-MB elevation in patients with unstable angina or angiographic thrombus at screening. Furthermore, in the GUSTO-I trial, diabetic patients also had lower levels of creatine kinase release compared with nondiabetics. ${ }^{21}$ These findings may be explained by a decline in creatine kinase activity related to diabetes as demonstrated in animal studies.22,23 Finally, intensified medical management in the treatment of these high-risk patients, either in the time interval between screening and surgery or during the procedure, cannot be completely ruled out as an explanation for our findings.

\section{Clinical Implications}

The level of CK-MB was shown to be an independent predictor of clinical events in this population treated with bypass surgery. Patients with elevated CK-MB levels, particularly those with levels $>5$ times normal, were at higher risk of death or myocardial infarction compared with those with normal or mild cardiac enzyme elevation. This finding has not previously been reported in a large prospective multicenter trial. In fact, the difficulty in determining clinically relevant myocardial injury during $\mathrm{CABG}^{24}$ has led to the common belief that cardiac enzymes have limited prognostic value in this setting. ${ }^{25} \mathrm{~A}$ limited number of investigations have reported the incidence of CK-MB elevation after CABG, ${ }^{26,27}$ and virtually no previous study has addressed the long-term prognostic significance of this biochemical marker.

Based on our findings, increased CK-MB may be considered as a marker of worse outcome after CABG and patients with markedly increased levels of CK-MB $(>5 \times$ normal) should be treated as a high-risk population for subsequent clinical events (death and/or MI) occurring as early as 30 days postoperatively. Because a trend toward a higher mortality rate was also observed in patients with CK-MB elevations $>3$ to $5 \times$ normal, these patients may also be considered at increased risk. Our data justify routine measurement of cardiac enzymes in patients treated with bypass surgery, especially in future clinical trials, in order to confirm these findings.

\section{Acknowledgments}

We thank Dr Brian Firth for his careful review of the manuscript and for his constructive comments.
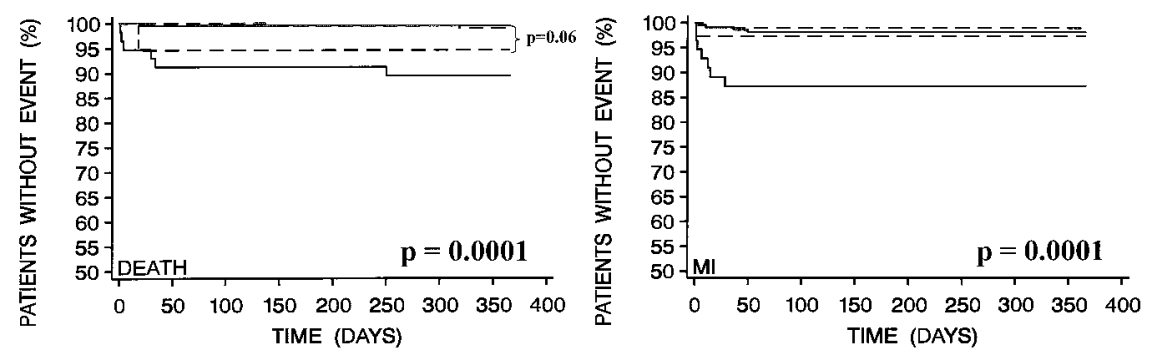

Figure 3. Kaplan-Meier curves illustrating the incidence of death and myocardial infarction (MI) at 1-year follow-up in patients with normal CK-MB levels (dashed gray lines), $>1$ to 3 times normal (solid gray lines), $\geq 3$ to 5 times normal (dashed black lines), and $>5$ times normal (solid black lines) after bypass surgery. The $P$-value refers to the comparison among the 4 groups. 


\section{References}

1. Califf RM, Abdelmeguid AE, Kuntz RE, et al. Myonecrosis after revascularization procedures. J Am Coll Cardiol. 1998;31:241-251.

2. Harrington RA, Lincoff AM, Califf RM, et al. Characteristics and consequences of myocardial infarction after percutaneous coronary intervention: insights from the Coronary Angioplasty Versus Excisional Atherectomy Trial (CAVEAT). J Am Coll Cardiol. 1995;25:1693-1699.

3. Abdelmeguid AE, Topol EJ. The myth of the myocardial 'infarctlet' during percutaneous coronary revascularization procedures. Circulation. 1996;94:3369-33675.

4. Abdelmeguid AE, Topol EJ, Whitlow PL, et al. Significance of mild transient release of creatine kinase-MB fraction after percutaneous coronary interventions. Circulation. 1996;94:1528-1536.

5. Kong TQ, Davidson CJ, Meyers SN, et al. Prognostic implication of creatine kinase elevation following elective coronary artery interventions. JAMA. 1997;277:461-466.

6. Topol EJ, Ferguson JJ, Weisman HF, et al. Long-term protection from myocardial ischemic events in a randomized trial of brief integrin $\beta 3$ blockade with percutaneous coronary intervention: EPIC Investigator Group, Evaluation of Platelet IIb/IIIa Inhibition for Prevention of Ischemic Complication. JAMA. 1997;278:479-484.

7. Tardiff BE, Califf RM, Tcheng JE, et al. Clinical outcomes after detection of elevated cardiac enzymes in patients undergoing percutaneous intervention: IMPACT-II Investigators, Integrilin (eptifibatide) to Minimize Platelet Aggregation and Coronary Thrombosis-II. J Am Coll Cardiol. 1999;33:88-96.

8. Simoons ML, van den Brand M, Lincoff M, et al. Minimal myocardial damage during coronary intervention is associated with impaired outcome. Eur Heart J. 1999;20:1112-1119.

9. Klein LW, Kramer BL, Howard E, et al. Incidence and clinical significance of transient creatine kinase elevations and the diagnosis of non-Q wave myocardial infarction associated with coronary angioplasty. J Am Coll Cardiol. 1991;17:621-626.

10. Saucedo JF, Mehran R, Dangas G, et al. Long-term clinical events following creatine kinase-myocardial band isoenzyme elevation after successful coronary stenting. J Am Coll Cardiol. 2000;35:1134-1141.

11. Warren SG, Wagner GS, Bethea CF, et al. Diagnostic and prognostic significance of electrocardiographic and CPK isoenzyme changes following coronary bypass surgery: correlation with findings at one year. Am Heart J. 1977;93:189-196.

12. Machler H, Metzler H, Sabin K, et al. Preoperative myocardial cell damage in patients with unstable angina undergoing coronary artery bypass graft surgery. Anesthesiology. 1994;81:1324-1331.

13. Serruys PW, Unger F, Sousa JE, et al. Comparison of coronary-artery bypass surgery and stenting for the treatment of multivessel disease. $N$ Engl J Med. 2001;344:1117-1124.
14. Sylven C, Jansson E, Olin C. Human myocardial and skeletal muscle enzyme activities: creatine kinase and its isozyme MB as related to citrate synthase and muscle fibre types. Clin Physiol. 1983;3:461-468.

15. Lee ME, Sethna DH, Conklin CM, et al. CK-MB release following coronary artery bypass grafting in the absence of myocardial infarction. Ann Thorac Surg. 1983;35:277-279.

16. Ahmed SA, Williamson JR, Roberts R, et al. The association of increased plasma MB CPK activity and irreversible ischemic myocardial injury in the dog. Circulation. 1976;54:187-193.

17. Weightman WM, Gibbs NM, Sheminant MR, et al. Drug therapy before coronary artery surgery: nitrates are independent predictors of mortality and beta-adrenergic blockers predict survival. Anesth Analg. 1999;88: $286-291$.

18. Boldt J, Rothe G, Schindler E, et al. Can clonidine, enoximone, and enalaprilat help to protect the myocardium against ischaemia in cardiac surgery? Heart. 1996;76:207-213.

19. Laskey WK. Beneficial impact of preconditioning during PTCA on creatine kinase release. Circulation. 1999;99:2085-2089.

20. Kloner RA, Shook T, Przyklenk K, et al. Previous angina alters in-hospital outcome in TIMI 4: a clinical correlate to preconditioning? Circulation. 1995;91:37-45.

21. Mak KH, Moliterno DJ, Granger CB, et al. Influence of diabetes mellitus on clinical outcome in the thrombolytic era of acute myocardial infarction: GUSTO-I Investigators, Global Utilization of Streptokinase and Tissue Plasminogen Activator for Occluded Coronary Arteries. J Am Coll Cardiol. 1997;30:171-179.

22. Popovich BK, Sayen MR, Dillmann WH. Insulin responsiveness of CK-M and CK-B mRNA in the diabetic rat heart. Am J Physiol. 1991; 261:E377-E381.

23. Su CY, Payne M, Strauss AW, et al. Selective reduction of creatine kinase subunit mRNAs in striated muscle of diabetic rats. Am J Physiol. 1992; 263:E310-E316.

24. Hodakowski GT, Craver JM, Jones EL, et al. Clinical significance of perioperative Q-wave myocardial infarction: the Emory Angioplasty versus Surgery Trial. J Thorac Cardiovasc Surg. 1996;112:1447-1453.

25. Force T, Hibberd P, Weeks G, et al. Perioperative myocardial infarction after coronary artery bypass surgery: clinical significance and approach to risk stratification. Circulation. 1990;82:903-912.

26. Bonnefoy E, Filley S, Kirkorian G, et al. Troponin I, troponin T, or creatine kinase-MB to detect perioperative myocardial damage after coronary artery bypass surgery. Chest. 1998;114:482-486.

27. van der Laarse A, Davids HA, Hollaar L, et al. Recognition and quantification of myocardial injury by means of plasma enzyme and isoenzyme activities after cardiac surgery. Br Heart J. 1979;41:660-667. 